\title{
Effect of Early Feed Restriction of Varied Severity on Growth Performance, Carcass Composition and Lipid Metabolism in Female Ducks
}

\author{
Ben-Jie TAN, Shigeru OHTANI ${ }^{1}$ and Kei-ichi TANAKA ${ }^{2}$ \\ The United Graduate School of Agricultural Science, Gifu University, Gifu-shi 501-1193, Japan \\ ${ }^{1}$ Faculty of Agriculture, Gifu University, Gifu-shi 501-1193, Japan \\ ${ }^{2}$ Graduate School of Agriculture, Hokkaido University, Kita-Ku, Sapporo-shi 060-8589, Japan
}

(Received November 27, 1998 ; Accepted June 16, 1999)

\begin{abstract}
This experiment was carried out using female ducks to determine the effect of feed restriction at early stage of growth of varied severity on subsequent growth performance, carcass composition and lipid metabolism. Seventy-two meat-type female ducks (White Peking) were assigned to four treatments at 7 days of age : ad libitum feeding (control) and three treatments, in which daily feed intake were designed to restrict to 80,60 and $40 \%$ of ad libitum intake, respectively from 8 to 14 days of age. All the birds were fed ad libitum following feed restriction until 47 days of age. A commercial starter diet for broilers $(2,900 \mathrm{kcal} \mathrm{ME} / \mathrm{kg}$ of diet, $23 \% \mathrm{CP})$ was supplied to all the birds from 1 to 21 days of age followed by a finisher diet for broilers $(3,200 \mathrm{kcal} \mathrm{ME} / \mathrm{kg}$ of diet, $19 \% \mathrm{CP})$ up to 47 days of age. Six ducks from each group were killed at 14 days of age and the remainders were sacrificed at the final day of experiment. The growth rate was significantly lowered by feed restriction but it was completely recovered irrespective of the severity of restriction until the experiment terminated. Weights of muscle and abdominal fat pad were also decreased by the feed restriction at 14 days of age. However, there were no differences between control and feed-restricted groups when the experiment terminated at 47 days of age. Visceral weights and carcass composition were measured only at 47 days of age and no effect of feed-restriction was observed. Lipid metabolism was also significantly affected by the feed restriction at 14 days of age as evidenced by decreases in contents of triglyceride and phospholipid in the liver and serum and activities of liver acetyl-CoA carboxylase and fatty acid synthetase while these effects were not observed in the birds killed at 47 days of age.
\end{abstract}

Animal Science Journal 70 (5) : 297 305, 1999

Key words : Duck, Early feed restriction, Lipid metabolism, Compensatory growth, Carcass composition

The carcass of ducks is characterized to contain a large amount of fat, which represents over $30 \%$ of carcass weight ${ }^{2,13,20 ?}$. Obesity in ducks is mainly caused by feeding diets with wide energy : protein $\operatorname{ratios}^{29)}$, selection for a rapid growth ${ }^{30)}$ and overconsumption $^{27)}$. Like broiler chickens, excessive fat results in not only an undesirable marketing feature but also in production inefficiency. It has been suggested that high fat deposition is one of the major reasons resulting in a poorer feed conversion in ducks, when compared to broiler chickens ${ }^{12)}$. Improvement in carcass quality as well as growth performance by decreasing carcass fat deposition has become a hot issue facing the meat-type duck production.

Early feed restriction has been applied to reduce body fat and to improve poor feed efficiency and metabolic diseases in broiler chickens. Plavnik et al. 25), and Plavnik and Hurwitz $z^{21-24)}$ demonstrated that early feed restriction resulted in an improvement in feed efficiency and a reduction in carcass lipid content

Corresponding : Shigeru OHTANI (fax : + 81(0) 58-293-2871, e-mail : sohtani@cc.gifu-u.ac.jp)

Anim. Sci. J. 70 (5) : 297-305, 1999 


\section{TAN, OHTANI and TANAKA}

but not in body weight at a market age in broiler chickens. Many investigators, 10, 14,28,34) confirmed the phenomenon of compensatory growth and reported improvement in feed utilization and/or reduction in body fat deposition in broiler chickens subjected to an early feed restriction. Such phenomenon has been attributed to early feed restriction to alter growth curve ${ }^{21}$, changes in hormonal ${ }^{16)}$ and lipogenic responses ${ }^{28 !}$, and control of hyperplasia and/ or hypertrophy of adipocytes ${ }^{21,33,36)}$. Because meattype ducks contain more carcass fat than broiler chickens at a market age ${ }^{2,20)}$, early feed restriction may benefit more duck production than broiler production if fat deposition could be reduced by feed restriction. Unfortunately, the methodology of feed restriction in meat-type ducks has not been adequately explored yet. Furthermore, effect of early feed restriction on lipid metabolism is hardly investigated in ducks. Thus, this study was conducted using ducks to examine the effects of early feed restriction of varying degrees on 1) growth performance and meatproduction, 2) abdominal fat pad weights and carcass fat contents, 3) activities of hepatic lipogenic enzymes and 4) lipid contents in the liver and serum.

\section{Materials and Methods}

\section{Animals and diets}

Seventy-two day-old female meat-type ducks (White Peking) were purchased from a commercial hatchery (Takahashi hatchery, Osaka, Japan). They were reared within a windowless house and an electrically-heated brooder was used to provide a supplemental source of heat until 14 days of age. Temperature in the brooder was maintained at $32 \pm 1{ }^{\circ} \mathrm{C}$ for 5 days and then gradually reduced in keeping with usual brooding practice where room temperature was maintained at $23 \pm 3^{\circ} \mathrm{C}$ throughout the experiment. During the pre-experimental period ( 1 to $7 \mathrm{~d}$ ), feed was given ad libitum to all birds. At 8 days of age, ducks were identified with shank bands and distributed to 4 treatment groups with two replicates of 9 ducks each where the average body weights were similar. The treatments encompassed four levels of feeding regimen, namely an ad libitum (control) and $80 \%, 60 \%$ and $40 \%$ of ad libitum feeding treatments, respectively. Feed intake in ducks was restricted from 8 to 14 days of age. During this period, daily feed allowance in the restricted ducks was determined by feed intake of the control ducks on the previous day. Ad libitum feeding was resumed following feed restriction until the end of the experiment. A commercial starter diet for broilers $(2,900 \mathrm{kcal} \mathrm{ME} / \mathrm{kg}$ of diet, $23 \% \mathrm{CP}$ ) was fed to all birds from 1 to 21 days of age. This was followed by a commercial finisher diet for broilers $(3,200 \mathrm{kcal} \mathrm{ME} / \mathrm{kg}$ of diet, $19 \% \mathrm{CP})$ from 22 to 47 days. Body weight was recorded each week individually, whereas feed consumption was determined daily.

\section{General procedure}

At 14 and 47 days of age, 6 ducks of each treatment group with similar body weight to the pen average were bled by jugular veins for blood samples (approximately $20 \mathrm{ml}$ per bird) and were killed by decapitation. The sampling and killing of ducks were conducted in rotation. The serum was separated by centrifugation (Model 05P-21, Hitachi koki LTD, Tokyo, Japan) at $650 \times \mathrm{g}$ for 10 minutes. The liver and abdominal fat pad were removed immediately and weighed. One part of each liver was put into an ice-cold saline for determination of lipogenic enzyme activities. The remaining liver and serum were stored at $-30^{\circ} \mathrm{C}$ for subsequent analysis of the various lipid fractions. Various lipid fractions were determined using the IATROSCAN (TH-10, Iatron Laboratories Inc. Tokyo, Japan) thin layer chromatography-flame with ionization detector system (TLCFID) according to Christie and Hunter ${ }^{4)}$. At 47 days of age, the remaining 6 ducks of each group were starved overnight to empty the digestive tracts and bled to death through jugular vein. Then, the ducks were blanched at $60^{\circ} \mathrm{C}$ for about 2 minutes and placed in a rotary drum picker (Tazaki Seisakusho Co. Tokyo, Japan) for 30 seconds to remove feathers. The pinfeather was plucked carefully by hand. In the process of dissection, gastrointestinal tract was cut and opened and washed away its contents. After removing the water with rags, the weights of gizzard and small intestine were determined, then the gastrointestinal tract was returned to the carcass. The carcasses, except for blood, feces and feathers were 
frozen at $-30^{\circ} \mathrm{C}$ until further analysis. When mincing, the carcasses from each pen were repeatedly ground four times using a meat grinder (Model WMG-22, Watanabe Seisakusho Co. Japan) with a 5 $\mathrm{mm}$ mesh plate. Finally, they were thoroughly ground and mixed by a blender (Model MK-K47-W, National Co. Osaka, Japan) to obtain uniform mixing. Protein, fat and moisture contents of carcasses were determined by the method of AOAC ${ }^{1)}$. Measurement of the abdominal fat pad, breast (M. Pectoralis major) and leg (M. Femoris and $M$. Cruris) muscles in this study were based on the procedure of Leeson et al. ${ }^{13)}$.

\section{Treatment of liver sample}

Liver was cut with scissors into small pieces, then homogenized for 30 seconds (Model LK-21, Ultradisperser, Yamato Co. Japan) in $0.25 \mathrm{M}$ sucrose solution containing $1 \mathrm{mM}$ ethylenediaminetetraacetate- 2 $\mathrm{Na}$ (EDTA-2 Na) under the ice-bath condition. The homogenates were then centrifuged (Model RS-18, Tomy Seiko, Japan) at $600 \times \mathrm{g}$ at $4^{\circ} \mathrm{C}$ for 10 minutes. The supernatants were recentrifuged (Model 65P, RP 40705 rotor, Hitachi koki LTD, Tokyo, Japan) at $105,000 \times \mathrm{g}$ at $4^{\circ} \mathrm{C}$ for 60 minutes. The supernatants (cytosolic fraction) were used for enzyme activity determinations.

\section{Enzyme assay}

Acetyl-CoA carboxylase (EC, 6.2.1.3, ACC) was assayed by $\mathrm{H}^{14} \mathrm{CO}_{3}$-fixation method ${ }^{26)}$, and fatty acid synthetase (FAS) was assayed by $1-{ }^{14} \mathrm{C}$-acetyl-CoA incorporation method ${ }^{8)}$. The protein content of solutions used for enzyme assay was determined by the method of Lowry et al. ${ }^{15)}$ using albumin as the standard. Enzyme activities were expressed as nanomole of substrate converted to product per minute per $\mathrm{mg}$ protein at $37^{\circ} \mathrm{C}$.

\section{Statistical analyses}

All data were statistically analyzed using one-way analyses of variance (ANOVA), and significant differences among treatments were determined by Duncan's multiple range test ${ }^{5)}$ at the level of $\mathbf{P}<0.05$. Percentages were transformed to arc sine percentages before square root percentages ANOVA was performed.

\section{Results}

Effects of early feed restriction on body weight, feed intake and feed conversion ratio of ducks are shown in Table 1. At the end of the 7 days feed restriction, the body weight was smaller for all feed-restricted ducks than for control ducks. At 47 days of age, however, the restricted-refed ducks achieved body weight equal to controls regardless of the severity of feed restriction. The body weight gain from 15 to 47 days of age tended to be higher in previously feed-restricted birds than in control group, so that no significant difference in weight gain was found among the treatment groups throughout the experimental period. Feed intake (15 to 47 days and 7 to 47 days) was significantly lower in restricted-refed ducks than in control ducks and feed conversion ratios (7-47 days) were superior for previously restricted birds.

Effects of early feed restriction on the weights of liver, abdominal fat pad, gizzard, small intestine, breast and leg muscles, and dressed carcass are listed in Table 2. At 14 days of age, the liver and abdominal fat pad weights, expressed as percentage of body weights, linearly decreased with increasing degree of feed restriction, but not different among the treatment groups at 47 days of age. The proportions of breast (M. Pectoralis major) and leg (M. Femoris and $M$. Cruris) muscles weights to body weights decreased or tended to decrease in feed-restricted ducks at the end of 7 days feed restriction, but did not differ at 47 days of age. The percentage of dressed carcass weight was not affected by early feed restriction, whereas the percentage of gizzard and small intestine tended to increase in previously feed-restricted ducks.

Table 3 shows the effects of early feed restriction on carcass composition in female ducks. Early feed restriction, regardless of severity, did not change the carcass composition of ducks at a market age although ducks fed $40 \%$ ad libitum tended to reduce carcass fat content.

The effects of early feed restriction on hepatic ACC and FAS activities are presented in Table 4. With increasing degree of feed restriction, hepatic FAS activity decreased at the end of 7 days feed restriction. ACC activity in the liver of feed-restricted ducks 
TAN, OHTANI and TANAKA

Table 1. Effectes of early feed restriction on body weight, weight gain and feed conversion ratio of female ducks

\begin{tabular}{|c|c|c|c|c|}
\hline \multirow{2}{*}{ Variable } & \multirow{2}{*}{ Ad libitum } & \multicolumn{3}{|c|}{ Restricted to } \\
\hline & & $80 \%$ & $60 \%$ & $40 \%$ \\
\hline \multicolumn{5}{|l|}{ 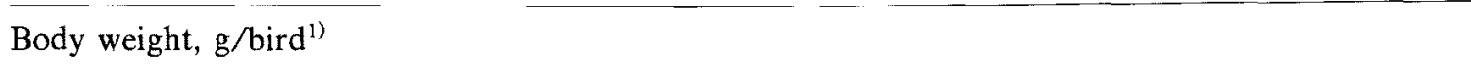 } \\
\hline $7 \mathrm{~d}$ & $170 \pm 5$ & $170 \pm 4$ & $170 \pm 4$ & $170 \pm 5$ \\
\hline $14 \mathrm{~d}$ & $371 \pm 13^{\mathrm{a}}$ & $312 \pm 8^{b}$ & $272 \pm 8^{\mathfrak{c}}$ & $248 \pm 8^{d}$ \\
\hline $47 \mathrm{~d}$ & $2,775 \pm 60$ & $2,745 \pm 60$ & $2,808 \pm 48$ & $2,777 \pm 62$ \\
\hline \multicolumn{5}{|l|}{ Weight gain, $g /$ bird $^{1)}$} \\
\hline $7-14 d$ & $210 \pm 6^{a}$ & $142 \pm 1^{b}$ & $102 \pm 1^{\mathrm{c}}$ & $78 \pm 2^{d}$ \\
\hline $15-47 d$ & $2,404 \pm 74$ & $2,433 \pm 23$ & $2,536 \pm 23$ & $2,529 \pm 73$ \\
\hline $7-47 d$ & $2,605 \pm 68$ & $2,575 \pm 24$ & $2,638 \pm 22$ & $2,607 \pm 73$ \\
\hline \multicolumn{5}{|l|}{ Feed intake, $g /$ bird $^{2)}$} \\
\hline $7-14 d$ & $507 \pm 2$ & $365 \pm 7$ & $276 \pm 5$ & $183 \pm 12$ \\
\hline $15-47 d$ & $6,898 \pm 67^{a}$ & $6,320 \pm 55^{b}$ & $6,816 \pm 25^{\mathbf{a}}$ & $6,243 \pm 98^{b}$ \\
\hline $7-47 d$ & $7,405 \pm 65^{a}$ & $6,685 \pm 48^{b}$ & $7,092 \pm 20^{a}$ & $6,426 \pm 102^{b}$ \\
\hline \multicolumn{5}{|c|}{ Feed conversion ratio, $\mathrm{g} / \mathrm{g}^{2)}$} \\
\hline $7-47 d$ & $2.84 \pm 0.05^{\mathrm{a}}$ & $2.60 \pm 0.05^{b c}$ & $2.69 \pm 0.03^{b}$ & $2.47 \pm 0.03^{\circ}$ \\
\hline
\end{tabular}

1) Average and SE for 18 ducks (7-14d) and for 12 ducks (15-47d) each treatment.

2) Data are presented as the means and $S E$ for two replicates. Different superscripts within the same row indicate significant difference $(\mathrm{P}<0.05)$.

tended to decrease but not significantly. At 47 days of age, however, previously feed-restricted ducks had similar values in the activities of ACC and FAS in comparison with control ducks.

The effects of early feed restriction on the contents of various lipid fractions in the liver and serum of female ducks are shown in Tables 5 and 6 . At 14 days of age, the hepatic triglyceride content, as well as the serum triglyceride and phospholipid concentrations, significantly decreased in the feed-restricted ducks. At 47 days of age, however, lipid fractions in the liver and serum of restricted-refed ducks were not different from those of control ducks. During the period of feed restriction and refeeding, neither cholesterol ester nor free cholesterol levels in the liver and serum were affected by feed restriction.

\section{Discussion}

Plavnik and Hurwitz ${ }^{24)}$ showed a complete growth compensation at 56 days of age when fed restrictively at an early age in broiler chickens. In this study, we subjected ducks to an early feed restriction similar to that used by Plavnik and Hurwitz ${ }^{24)}$, and showed that restricted-refed ducks achieved body weight equal to those of controls at 47 days of age, irrespective of the severity. This observation indicated that ducks are more tolerant to severe feed restriction at early stage of growth than broiler chickens. It has been reported that hyperphagia and morphological adaptations of digestive tract (e.g. increase in weight) in restrictedrefed broilers were the major contributing factors to compensatory growth and improved feed efficiency ${ }^{35)}$. The present study clearly showed that feed restriction induces a typical concave growth in female duck. During recovery, the restricted-refed ducks gained more weight while consumed less feed than control ducks. But the difference was not statistically significant due to the number of observation. Weights of gizzard and small intestine did not increase by refeeding (Table 2). Obviously, compensatory growth associated with improved feed efficiency in those ducks could not be interpreted by hyperphagia or adaptive changes of digestive tracts. In rat, Kershaw et al. ${ }^{11)}$ and Windmarsh et al. ${ }^{32)}$ demonstrated that 
Effect of Early Feed Restriction in Ducks

Table 2. Effectes of early feed restriction on weight on liver, abdominal fat pad, gizzard, small intestine, breast and leg muscles, and dressed carcass in female ducks

Variable
Ad libitum

Liver
$14 \mathrm{~d}$
3. $\left.28 \pm 0.25^{\mathrm{a} 1}\right)$
2. $84 \pm 0.11^{\text {ab }}$
2. $78 \pm 0.11^{\mathrm{b}}$
$2.57 \pm 0.12^{b}$
$47 \mathrm{~d}$
1. $84 \pm 0.08$
$1.88 \pm 0.07$
1. $75 \pm 0.08$
$1.82 \pm 0.05$

Abdominal fat pad
$14 \mathrm{~d}$
$0.33 \pm 0.03^{2}$
$0.21 \pm 0.05^{a b}$
$0.16 \pm 0.05^{\mathrm{bc}}$
$0.12 \pm 0.05^{\circ}$
$47 \mathrm{~d}$
1. $88 \pm 0.13$
1. $99 \pm 0.13$
2. $11 \pm 0.08$
2. $00 \pm 0.11$

Right breast muscle
$14 \mathrm{~d}$
$0.56 \pm 0.03^{\mathrm{a}}$
$0.51 \pm 0.02^{\mathrm{a}}$
$0.47 \pm 0.01^{\mathrm{b}}$
$0.45 \pm 0.02^{b}$
$47 \mathrm{~d}$
3. $71 \pm 0.11$
3. $69 \pm 0.20$
3. $72 \pm 0.13$
3. $67 \pm 0.12$

Right leg muscle
$14 \mathrm{~d}$
5. $83 \pm 0.19^{\mathrm{a}}$
5. $50 \pm 0.33^{\mathrm{ab}}$
5. $27 \pm 0.16^{\text {ab }}$
4. $83 \pm 0.47^{\mathrm{b}}$
$47 d$
4. $22 \pm 0.12$
4. $50 \pm 0.28$
1. $02 \pm 0.13$
4. $28 \pm 0.17$

Gizzard
$47 \mathrm{~d}$
$2.96 \pm 0.16$
$3.03 \pm 0.08$
$3.06 \pm 0.18$
$3.07 \pm 0.25$

Small intestine

$47 \mathrm{~d}$

$2.08 \pm 0.20$

$2.02 \pm 0.20$

$2.19 \pm 0.35$

2. $29 \pm 0.41$

Dressed carcass ${ }^{2)}$

$47 \mathrm{~d}$

$85.5 \pm 0.65 \quad 85.0 \pm 0.54$

$86.9 \pm 1.86$

$86.2 \pm 0.76$

1) Average and SE for 6 ducks (14d) and for 12 ducks (47 d) each treatment.

2) Dressed carcass percentage $=$ carcass weight/body wight $\times 100 \%$. Different superscripts within the same row indicate significant difference $(P<0.05)$.

Table 3. Effectes of early feed restriction on carcass composition of female ducks at 47 days of age

\begin{tabular}{llccc}
\hline Variable & Ad libitum & \multicolumn{3}{c}{ Restricted to } \\
\cline { 3 - 5 } & & $80 \%$ & $60 \%$ & $40 \%$ \\
\hline Protein & $14.1 \pm 0.23^{1)}$ & $14.1 \pm 0.12$ & $14.0 \pm 0.10$ & $14.3 \pm 0.35$ \\
Fat & $28.1 \pm 0.98$ & $28.1 \pm 0.49$ & $28.5 \pm 1.13$ & $27.6 \pm 1.54$ \\
Moisture & $55.3 \pm 0.77$ & $55.4 \pm 0.44$ & $54.7 \pm 1.45$ & $55.5 \pm 1.23$ \\
\hline
\end{tabular}

${ }^{1)}$ Data are presented as means and SE for 6 ducks per treatment. Different superscripts within the same row indicate significant difference $(P<0.05)$.

dietary restriction increased the absorption rate of amino acids in the intestine. Nitsan et al. ${ }^{18)}$ also reported that digestibility and activities of digestive enzymes increased in feed-restricted chicks. It seems likely that metabolic shift in enhanced digestion and absorption of nutrients occurred in restricted-refed 
Table 4. Effectes of early feed restriction on activities of acetly-CoA carboxylase (ACC) and fatty acid synthetase (FAS) in the liver of female ducks

\begin{tabular}{|c|c|c|c|c|}
\hline \multirow{2}{*}{ Enzymes } & \multirow{2}{*}{ Ad libitum } & \multicolumn{3}{|c|}{ Restricted to } \\
\hline & & $80 \%$ & $60 \%$ & $40 \%$ \\
\hline & \multicolumn{4}{|c|}{ (nmole/min/mg protein) } \\
\hline \multicolumn{5}{|c|}{ Acetly-CoA carboxylase } \\
\hline $14 d$ & $2.91 \pm 0.21^{1)}$ & $2.90 \pm 0.22$ & $2.60 \pm 0.36$ & $2.55 \pm 0.69$ \\
\hline $47 \mathrm{~d}$ & $4.14 \pm 1.05$ & $4.12 \pm 0.87$ & $4.40 \pm 1.09$ & $4.63+0.89$ \\
\hline \multicolumn{5}{|c|}{ Fatty acid synthetase } \\
\hline $14 \mathrm{~d}$ & $3.48 \pm 0.37^{\mathrm{a}}$ & $2.51 \pm 0.45^{\mathrm{ab}}$ & $2.03 \pm 0.35^{b}$ & $2.08 \pm 0.19^{\mathrm{t}}$ \\
\hline $47 d$ & $1.32 \pm 0.50$ & $0.99 \pm 0.37$ & $1.00 \pm 0.33$ & $1.16 \pm 0.43$ \\
\hline
\end{tabular}

1) Values represent means $\pm S E$ for 6 ducks per treatment. Different superscripts within the same row indicate significant difference $(\mathrm{P}<0.05)$.

Table 5. Effectes of early feed restriction on lipids contents in the liver of female ducks

\begin{tabular}{lrrrr}
\hline \hline \multirow{2}{*}{ Variable } & Ad libitum & \multicolumn{3}{c}{ Restricted to } \\
\cline { 4 - 5 } & & \multicolumn{1}{c}{$80 \%$} & $60 \%$ & $40 \%$ \\
\hline 14d & & & & \\
Triglyceride & $\left.16.96 \pm 4.47^{\mathrm{a})}\right)$ & $5.50 \pm 0.82^{\mathrm{b}}$ & $5.38 \pm 1.62^{\mathrm{b}}$ & $5.65 \pm 0.95^{\mathrm{b}}$ \\
Feel cholesterol & $3.06 \pm 0.19$ & $3.36 \pm 0.09$ & $3.15 \pm 0.06$ & $3.07 \pm 0.10$ \\
Phospholipid & $21.55 \pm 2.29$ & $21.15 \pm 2.29$ & $20.42 \pm 1.63$ & $21.16 \pm 1.20$ \\
47 d & & & & \\
Triglyceride & $3.51 \pm 2.38$ & $1.1 .06 \pm 4.08$ & $6.82 \pm 3.30$ & $4.84 \pm 0.90$ \\
Feel cholesterol & $3.12 \pm 0.27$ & $2.93 \pm 0.15$ & $3.27 \pm 0.07$ & $3.17 \pm 0.22$ \\
Phospholipid & $23.59 \pm 2.67$ & $21.96 \pm 2.39$ & $17.92 \pm 1.38$ & $17.78 \pm 1.82$ \\
\hline
\end{tabular}

1) Values represent means \pm SE for 6 ducks per treatment. Different superscripts within the same row indicate significant difference $(\mathrm{P}<0.05)$.

ducks, which results in compensatory growth and improved feed efficiency. Detailed studies on nutrient metabolism in restricted-refed ducks are needed to elucidate the mechanism involved in improvement of feed efficiency.

Newcombe et $a{ }^{17}{ }^{17)}$ observed a reduction in breast meat yield for broilers at market age due to early feed restriction. The present study showed that reduced weights of breast and leg muscles in feed-restricted ducks occurred at the end of the 7 days feed restriction, but not at a market age (Table 2). Pinchasov et $a l{ }^{19)}$ reported that feed deprivation caused a decrease in the breast muscle weight and refeeding resulted in an increase in growth rate of breast muscles. Hayashi et al. ${ }^{7)}$ showed that fasting-refeeding broiler chickens exhibited an increased rate of muscle protein turnover during the refeeding period. Knizetova et $a l .{ }^{12)}$ pointed out that the intensive growth of breast muscles in ducks occurred between 6-8 weeks of age. In the present study, we also demonstrated that early feed restriction did not affect the dressed carcass percentage of ducks at market age, suggesting that meat yield of ducks was unchanged when feed restriction was imposed at an early age. 
Effect of Early Feed Restriction in Ducks

Table 6. Effectes of early feed restriction on lipids contents in the serum of female ducks

\begin{tabular}{|c|c|c|c|c|}
\hline \multirow{2}{*}{ Variable } & \multirow{2}{*}{ Ad libitum } & \multicolumn{3}{|c|}{ Restricted to } \\
\hline & & $80 \%$ & $60 \%$ & $40 \%$ \\
\hline & \multicolumn{4}{|c|}{ (mg/100 ml serum) } \\
\hline \multicolumn{5}{|l|}{$14 \mathrm{~d}$} \\
\hline Cholesterol ester & 214.40 上10.71 & $189.43 \pm 7.22$ & $186.34 \pm 8.82$ & $207.26 \pm 9.85$ \\
\hline Triglyceride & $47.61 \pm 3.92^{\mathrm{a}}$ & $20.44 \pm 2.39^{b}$ & $22.25 \pm 2.69^{b}$ & $24.95 \pm 4.66^{b}$ \\
\hline Free cholesterol & $65.43 \pm 3.46$ & $63.47 \pm 4.27$ & $61.99 \pm 5.51$ & $66.66 \pm 3.45$ \\
\hline Phospholipid & $255.11 \pm 26.51^{a}$ & $188.50 \pm 21.82^{b}$ & $170.86 \pm 10.13^{b}$ & $162.62 \pm 9.37^{\mathrm{b}}$ \\
\hline \multicolumn{5}{|l|}{$47 \mathrm{~d}$} \\
\hline Cholesterol ester & $176.64 \pm 16.05$ & $188.86 \pm 8.97$ & $163.48 \pm 10.93$ & $168.65 \pm 3.68$ \\
\hline Triglyceride & $32.47 \pm 5.61$ & $39.57 \pm 2.65$ & $31.51 \pm 2.61$ & $34.52 \pm 5.79$ \\
\hline Free cholesterol & $52.71 \pm 3.21$ & $50.48 \pm 2.03$ & $47.40 \pm 1.97$ & $45.92 \pm 2.15$ \\
\hline Phospholipid & $205.35 \pm 22.59$ & $237.86 \pm 31.83$ & $214.99 \pm 22.44$ & $229.45 \pm 28.50$ \\
\hline
\end{tabular}

1) Values represent means \pm SE for 6 ducks per treatment. Different superscripts within the same row indicate significant difference $(\mathbf{P}<0.05)$.

Rosebrough et al. ${ }^{28)}$ showed that early feed restriction in broiler chickens resulted in a decrease in body fat content without reducing the general performance at a market age. They demonstrated that reduced body fat deposition was due to suppression of the activities of lipogenic-related enzymes. In this study, we observed that activities of fatty acid synthetase (FAS) in feed-restricted ducks were depressed at the end of feed restriction at 14 days of age (Table 4). The carcass fat content at a market age was not different among the treatment groups in the present experiment although it has been reported that carcass fat content of ducks was sensitive to change in amount of feed intake at a later stage of growth ${ }^{3)}$. It is likely that resumption of ad libitum feeding allow feedrestricted ducks to exhibit compensatory growth not only in muscle tissues but also in adipose tissues. This hypothesis could be partly proven by carcass fat contents, lipogenic enzyme activities and lipid contents in the restricted-refed ducks (Tables 3, 4, 5 and 6). Many factors may influence the effect of early feed restriction on reducing the body fat content. Summers et al. ${ }^{31)}$ reported that female broilers were less responsive than male broilers in reducing abdominal fat weight due to early feed restriction. Campbell et al. ${ }^{3)}$ stated that female ducks ac-

Anim. Sci. J. 70 (5) : 297-305, 1999 cumulated energy more as fat and less as protein than males. On the other hand, Evans ${ }^{6)}$ showed that fat depots in the domestic duck occur first in inguinal region at early stage of growth, following in subcutaneous tissue at younger age, and finally in abdominal adipose tissue at a later stage of growth. These observations suggest that the sex and timing of feed restriction may be the important factors affecting success in reducing carcass fat content of ducks.

In conclusion, ducks subjected to early feed restriction from 8 to 14 days of age fully recovered body weight and meat yield and improved feed efficiency at a market age. Success in reducing carcass fat deposition by early feed restriction in meat-type ducks will contribute to selecting a suitable method.

\section{Acknowledgements}

The authors gratefully acknowledge the technical assistance of Y. Komada, T. Yamazaki, C. Bunchasak and Adrizal.

\section{References}

1) Association of Official Analytical Chemists (AOAC). Official Methods of Analysis. 13th ed. Association of Official Analytical Chemists. Washington, DC. 1980. 
TAN, OHTANI and TANAKA

2) Auckland JN. Effect of feeding restricted amounts of a medium and high protein diet on growth and body composition of duckling. Journal of the Science of Food and Agriculture, 24 : 719-726. 1973.

3) Campbell RG, Karunajeewa H, Bagot I. Infuence of food intake and sex on the growth and Carcass composition of Pekin ducks. British Poultry Science, $26: 43-50.1985$.

4) Christie WW, Hunter ML. Separation of neutral lipids on chromarods. Journal of Chromatography, $171: 517-518.1979$.

5) Duncan DB. Multiple range and multiple test. Biometrics, $11:$ 1-42. 1955.

6) Evans AJ. Fat accretion during postembryonic growth in the domestic duck, with additional data from the Mallard. Physiological Zoology, 45:167177. 1972

7) Hayashi K, Nakano M, Toyomizu M, Tomita $Y$, Iwamoto T, Shika A. Effect of fasting early in life on performance, mortality and muscle protein metabolism of broiler chicken in high temperature environment. Japanese Journal of Zootechnical Science, 61 264-270. 1990.

8) Hsu RY, Wasson G, Porter JW. The purification and properties of the fatty acid synthetase of pigeon liver. The Journal of Biological Chemistry, $240: 3736^{-}$ 3746. 1965.

9) Jones GPD, Farrell DJ. Early-life food restriction of chicken. I. Method of application, amino acid supplementation and the age at which restriction should commence. British Poultry Science, 33 : 579588. 1992.

10) Jones GPD, Farrell DJ. Early-life food restriction of chicken. II. Effect of food restriction on the development of fat tissue. British Poultry Science, 33 : 589601. 1992.

11) Kershaw TG, Neame KD, Wiseman $G$. The effect of semistarvation on absorption by rat small intestine in vitro and in vivo. Journal of Physiology (London), 152 : 182-190. 1960.

12) Knizetova $\mathbf{H}$, Hyanek J, Knize B, Prochazkova $\mathbf{H}$. Analysis of growth curves of fowl. II. Ducks. British Poultry Science, 32 : 1039-1053. 1991.

13) Leeson S, Summers JD, Proulx J. Production and carcass characteristics of the duck. Poultry Science, $61: 2456-2464.1982$.

14) Leeson S, Summers JD, Caston LJ. Diet dilution and compensatory growth in broilers. Poultry Science, 70 : 867-873. 1991.

15) Lowry OH, Rosebrough NJ, Fart AL, Randell RJ.
Protein measurement with the folin phenol reagent. The Journal of Biological Chemistry, 193 : 265-275. 1951.

16) McMurtry JP, Plavnik I, Rosebrough RW, Stell NC, Proudman A. Effect of early feed restriction in male broiler chicks on plasma metabolic hormones during feed restriction and accelerated growth. Comparative Biochemistry and Physiology, 91 A : 67-70. 1988.

17) Newcombe M, Cartwright AL, Harter-Dennis JM. The effect of increasing photoperiod and feed restriction in sexed broiler-type birds. I. Growth and abdominal fat cellularity. British Poultry Science, 33 : 415-425. 1992.

18) Nitsan Z, Nir I, Petihi I. The effect of meal-feeding and food restriction on body composition, food utilization and intestinal adaptation in light-breed chicks. The British Journal of Nutrition, 51 : 101-109. 1984.

19) Pinchasov $Y, N i r$, Nitsan $Z$. The synthesis in vivo of protein in various tissues in chickens adapted to intermittent feeding. The British Journal of Nutrition, $60: 517-523.1988$.

20) Plavnik I, Hurwitz S, Barash H. The effect of feed restriction on the growth, feed conversion and fattening of Pekin ducks. Nutrition Reports International, $25: 907-911,1982$.

21) Plavnik I, Hurwitz S. The performance of broiler chicks during and following a severe feed restriction at an early age. Poultry Science, $64: 348-355.1985$.

22) Plavnik I, Hurwitz S. Early feed restriction in chicks : effect of age, duration and sex. Poultry Science, 67 : 384-390. 1988.

23) Plavnik I, Hurwitz S. Effect of dietary protein, energy and feed pelleting on response of chicks to early feed restriction. Poultry Science, 67 : 14071413. 1989

24) Plavnik I, Hurwitz S. Response of broiler chickens and turkey poults to food restriction of varied severity during early life. British Poultry Science, 32 : 343 -352. 1991 .

25) Plavnik I, McMurtry JP, Rosebrough RW. Effects of early feed restriction in broilers. I. Growth performance and carcass composition. Growth, $50: 68-76$. 1986.

26) Qureshi AA, Burger WC, Prentice N, Bird HR, Sunde ML. Regulation of lipid metabolism in chicken liver by dietary cereals. Joumal of Nutrition, 110 : 388-393. 1980.

27) Robert G. Elkin. A review on duck nutrition research. World's Poultry Science Journal, 43 : 84-106. 1987. 
28) Rosebrough RW, Steel NC, McMurtry JP, Plavnik I. Effect of early feed restriction in broiler. II. Lipid metabolism. Growth, $50: 217-227.1986$.

29) Scott ML, Hill FW, Parsons EH, Bruckner JH, Dougherty E. Studies on duck nutrition. 7. Effect of dietary energy : protein relationships upon growth, food utilization and carcass composition in market duckling. Poultry Science, 38 : 497-507. 1959.

30) Siregar AP, Cumning RB, Farrell DJ. The nutrition of meat-type ducks. 2. The effects of variation in the energy and protein contents of diets on the biological performance and carcass characteristics. Australian Journal of Agricultural Research, 33 : 865-875. 1982.

31) Summers JD, Spratt D, Atkinson JL. Restricted feeding and compensatory growth for broilers. Poultry Science, 69 : 1855-1861. 1990.

32) Windmarsh JT, Kilby D, Ross B, Wiseman G. Further studies on intestinal active transport during semistarvation. Journal of Physiology (London), 188 ;
207-218. 1967.

33) Zhong C, Nakaue HS, Hu CY, Mirosh LW. Effect of full feed and early feed restriction on broiler performance, abdominal fat level, cellularity, and fat metabolism in broiler chickens. Poultry Science, 74 : 1636-1643. 1995.

34) Zubair AK, Leeson S. Effect of varying period of early nutrient restriction on growth compensation and characteristics of male broilcrs. Poultry Science, 73 : 129-136. 1992.

35) Zubair AK, Leeson S. Effect of early feed restriction and realimentation on metabolic heat production and changes in digestive organs in broiler chickens. Poultry Science, 73 : 529-538. 1994.

36) Zubair AK, Leeson S. Changes in body composition and adipocyte cellularity of male broilers subjected to varying degrees of early-life feed restriction. Poultry Science, $75: 719-728.1996$. 